\title{
The Cinema Of Environmental Crisis
}

\author{
Co-presented by SFU Woodward's and the SFU Vancity Office of Community Engagement
}

\section{Djavad Mowafaghian World Art Centre, Goldcorp Centre for the Arts October 29, 2015, 7:00 pm}

Can films that depict urgent social problems challenge viewers to change their views? What is the boundary between images that can change the world, like the tragic image of the drowned Syrian boy, and images that cause us to turn away in a state of trauma, fatigue or willed ignorance? Does cinema (more than photography) run the risk of "aestheticizing" the suffering of people, ecosystems and other living things?

The global environmental crisis, encompassing climate change, dwindling natural resources, decimated rain forests and animal habitats, toxified industrial sites and acidic oceans, is a pressing problem that affects us all. But the majority of empowered citizens in industrialized economies have been slow realize the extent of the damage done (including our eradication of $50 \%$ of many animal species since the 1970s) and apathetic to streamline our lifestyles and consume less. While many citizens have remained poorly informed for decades due to the dominant media system built largely around corporate interests, others have chosen to ignore the mounting crisis. Psychologists call this process of willed ignorance disavowal, which can be a symptom of trauma. Cinematic representations are therefore of interest because they confront us with imagery we may prefer to ignore.

Dr. Anil Narine, editor of the book Eco-Trauma Cinema (Routledge 2015), will discuss this subgenre of eco-cinema in its three general forms: accounts of people who are traumatized by the natural world, narratives that represent people or social processes which traumatize the environment or its species, and stories that depict the aftermath of ecological catastrophe. Eco-trauma cinema represents the harm we, as humans, inflict upon our natural surroundings, or the injuries we sustain from nature in its unforgiving iterations. The term encompasses both circumstances because these seemingly distinct instances of ecological harm are often related and even symbiotic. In avant-garde, commercial, and documentary cinema, images of ecological trauma confront us. But to what end? Can these images of ecological trauma shock us in ways that activate us as citizens, rather than pacifying us as audiences? Might cinema be the "cognitive map" we need to enable us as to rethink our relationship with the imperiled natural world? 
Anil Narine has taught cinema studies and communication in the Department of Visual Studies and the Institute of Communication, Culture, Information and Technology at the University of Toronto since 2010. He returns to SFU where he studied in the School of Communication and now teaches in the Department of Sociology and Anthropology. He has been a visiting research student in the School of History of Art, Film and Visual Media at Birkbeck College, University of London, and in 2011-2012 he was a Postdoctoral Fellow in Film at Columbia University.

His research examines social networks, global inequalities, and sites of human and ecological trauma in the context of globalization and thickening global connections. He recently edited the book Eco-Trauma Cinema (Routledge 2015). Other publications appear in Communication, Culture \& Critique, Critical Studies in Media Communication, the Journal of American

Studies, Americana, Memory Studies and Theory, Culture \& Society. 